\title{
Eficiência térmica de telhas onduladas de fibrocimento aplicadas em abrigos individuais para bezerros expostos ao sol e à sombra
}

\author{
Thermal efficiency of fiber cement corrugated sheets applied to individual housing for calves \\ exposed to sun and shade
}

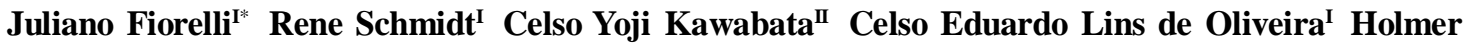 \\ Savastano Junior ${ }^{\mathrm{I}}$ João Adriano Rossignolo
}

\begin{abstract}
Este trabalho apresenta um estudo da eficiência térmica de coberturas de bezerreiros individuais expostas ao sol e à sombra, por meio de termografia infravermelha, temperatura interna e índices de conforto térmico. Foram avaliados quatro bezerreiros, três expostos ao sol, a saber: (i) cobertos com telhas de fibrocimento sem amianto - pintadas de branco, (ii) sem pintura e (iii) com sombrite posicionado internamente aos bezerreiros, à distância de $0,10 \mathrm{~m}$ da face inferior da telha. O quarto bezerreiro foi instalado em área sombreada e coberto com telhas de fibrocimento sem pintura. As coletas de dados foram realizadas durante 21 dias, nos horários das 11h00min, 14h00min e 17h00min. Os resultados mostraram variações significativas na temperatura de superfície das coberturas e nos índices de conforto térmico, entre os tratamentos expostos ao sol e à sombra, para todos os horários avaliados. As imagens termográficas infravermelhas mostraram-se eficientes para melhor compreensão dos processos de transferência de calor da cobertura para o interior das instalações.
\end{abstract}

Palavras-chave: bezerreiro, conforto térmico, termografia infravermelho.

\section{ABSTRACT}

This research presents a study of roof thermal efficiency in individual housing for calves exposed to sun and shade through infrared thermography, internal temperature and thermal comfort indexes. Four different individual housing for calves covered with asbestos-free fiber-cement corrugated sheets were evaluated. Three of them were directly exposed to the sun: (i) corrugated sheets painted white in the external surface, (ii) corrugated sheets without painting and (iii) with screen shade fabric installed $0.10 \mathrm{~m}$ under de internal surface of the corrugated sheet. The fourth individual housing was installed in the shade area and covered with unpainted corrugated fiber-cement sheets. The analysis was taken for 21 days at 11h00min, 14h00min and 17h00min. The results indicate significant variations in the roofing surface temperature and thermal comfort indexes among the treatments exposed to the sun and shade, for all the evaluations during the day. The infrared thermography images were effective for better understanding the heat transfer processes from the roof to the internal environment of the housing.

Key words: housing for calves, infrared thermograph, thermal comfort.

A renovação dos rebanhos de pecuária leiteira e de corte depende diretamente da sustentabilidade no sistema de criação de bezerros. $\mathrm{O}$ alcance de índices apropriados de produção da criação depende de fatores genéticos, alimentares, manejo sanitário e instalações adequadas. Nos rebanhos em que as vacas são ordenhadas sem a presença dos bezerros, é comum a separação de mãe e filho no momento do parto, ou no dia seguinte. Nessa situação, os bezerros são alojados em abrigos individuais ou coletivos denominados bezerreiros. Essas instalações devem ser capazes de amenizar as sensações de desconforto para o animal, além de oferecer condições adequadas de higiene (KAWABATA, 2003).

'Departamento de Engenharia de Alimentos, Faculdade de Zootecnia e Engenharia de Alimentos (FZEA), Universidade de São Paulo (USP), 13635-900, Pirassununga, SP, Brasil. E-mail: julianofiorelli@usp.br. *Autor para correspondência.

"Centro de Ciências Agrárias e Ambientais, Universidade Federal do Maranhão (UFMA), 65500-000, Chapadinha, MA, Brasil. 
A maioria das raças bovinas sofre estresse térmico em regiões quentes e com alta incidência de radiação, por serem oriundas de regiões de clima mais ameno. Uma alternativa para se evitar esse efeito é o uso de sombreamento (SILVA, 2000; CAMPOS et al., 2005).

Dentro desse escopo, o presente trabalho objetivou avaliar o ambiente térmico no interior de abrigos individuais para bezerros, expostos ao sol e à sombra, cobertos com telha de fibrocimento sem amianto (nova tecnologia - NT), utilizando termografia infravermelho e índices de conforto térmico.

Foram avaliados quatro bezerreiros individuais, construídos com estrutura de madeira serrada e fechamento lateral com placas de madeira compensada, pintadas com tinta PVA branca, com dimensões de $1,00 \mathrm{~m} \times 1,50 \mathrm{~m}$, cobertos com telha de fibrocimento sem amianto (NT), com dimensões nominais de $1,10 \mathrm{~m} \times 1,83 \mathrm{~m}$, espessura de $5 \mathrm{~mm}$. Os bezerreiros foram posicionados na direção leste-oeste e o piso do entorno foi forrado com areia grossa, como forma de garantir melhor condição de higiene nas imediações das instalações. As telhas foram avaliadas em quatro configurações: telha fibrocimento pintada de branco (TFCB), telha de fibrocimento sem pintura (TFC) e telha de fibrocimento com tela de sombreamento, "sombrite", posicionado na face inferior (TFCS), expostas ao sol. O conjunto telha + sombrite visa a minimizar o efeito de transmissão da radiação solar para o interior da edificação por meio da formação de um colchão de ar entre a telha e a tela sombrite, contribuindo com a redução da temperatura e consequentemente reduzindo o estresse térmico do animal. O quarto bezerreiro coberto com telha de fibrocimento sem pintura sombreada (TFCSomb) foi instalado sob sombra natural de árvores típicas da região (Sibipiruna - Caesalpinia peltophoroides), com diâmetro médio de $0,8 \mathrm{~m}$ e altura de $10 \mathrm{~m}$.

As avaliações foram realizadas durante 21 dias, nos horários das $11 \mathrm{~h} 00 \mathrm{~min}, 14 \mathrm{~h} 00 \mathrm{~min}$ e 17h00min, durante o período da primavera de 2009 (21/09-20/12) que costuma ser crítico na região, devido às temperaturas máximas elevadas, amplitudes térmicas diárias elevadas e pouca chuva. Os dados foram coletados apenas nos dias de sol. Para a análise dos índices de conforto térmico - Índice de Temperatura do Globo e Umidade (ITGU), Carga Térmica Radiante (CTR) e Índice de Temperatura e Umidade (ITU), foram utilizadas as equações propostas por BUFFINGTON et al. (1977), ESMAY (1969) e THOM (1958).

Com o auxílio do termovisor Fluke, modelo Ti20TM (Fluke Corporation, Everett, WA, USA), foram coletadas imagens termográficas das superfícies internas das coberturas dos bezerreiros. A leitura com câmera termográfica foi realizada a uma distância de aproximadamente $40 \mathrm{~cm}$ da superfície inferior interna da telha, abrangendo uma área de $0,5 \mathrm{~m}^{2}$.

Com os dados obtidos, foi realizada uma análise estatística segundo o delineamento em blocos casualizados (DBC) no esquema fatorial (4x3) - fator quatro corresponde ao acondicionamento térmico "cobertura" e o fator três corresponde às "horas de coleta". O fator acondicionamento térmico, formado por quatro níveis (TFC, TFCB, TFCS e TFCSomb) e o fator horas de coletas por três níveis $(11 \mathrm{~h} 00 \mathrm{~min}$, $14 \mathrm{~h} 00 \mathrm{~min}$ e $16 \mathrm{~h} 00 \mathrm{~min}$ ), totalizando doze tratamentos. Os dias de coletas dos dados climáticos foram considerados como repetições de cada tratamento. Com base na análise da ANOVA, procedeu-se ao Teste Tukey, a 5\% de probabilidade, para as variações dia, tratamento e horas, com o objetivo de investigar o comportamento das médias. Pela análise da variância (ANOVA), observa-se que não houve diferença estatística significativa $(\mathrm{P}<0,05)$, para os índices de conforto térmico (ITGU, CTR, ITU), entre os bezerreiros expostos ao sol no mesmo horário. Foi identificada diferença significativa $(\mathrm{P}<0,05)$ entre os índices de conforto térmico (ITGU, CTR, ITU), entre os horários determinados, para bezerreiros expostos ao sol. Comparando bezerreiros expostos ao sol (TFC, TFCB, TFCS) com bezerreiro exposto à sombra (TFCSomb), foi observada diferença significativa nos índices de conforto térmico CTR, ITU e Temperatura Ambiente, para todos os tratamentos em estudo.

É possível observar uma elevação no valor da CTR ao longo do dia para todas as coberturas avaliadas, atingindo índice máximo às $14 \mathrm{~h} 00 \mathrm{~min}$. Esse comportamento diurno da CTR foi constatado por NÄÄS et al. (2001) e FURTADO et al. (2003) e é explicado pelo fato de que os valores que definem a CTR ocorrem em função da radiação solar que, por sua vez, atinge os valores mais elevados próximo das $12 \mathrm{~h} 00 \mathrm{~min}$, quando o sol se posiciona de forma mais perpendicular ao plano do horizonte local e, também, em razão da radiação de ondas longas emitidas pela vizinhança. O mesmo comportamento foi observado para Temperatura Ambiente e Temperatura de Superfície. O bezerreiro exposto à sombra apresentou valores de CTR que diferem estatisticamente $(\mathrm{P}<0,05)$ dos outros abrigos expostos ao sol. $\mathrm{O}$ sombreamento natural promove um microclima diferenciado, que pode contribuir com os índices de produtividade de animais alojados nessas condições.

Ao se comparar os valores dos índices de conforto térmico ITGU e ITU, determinados no presente estudo, com aqueles de termoneutralidade para gado 
de leite indicados na literatura por THOM (1958), BAÊTA (1985) e CAMPOS et al. (2005), é possível afirmar que nenhum bezerreiro apresentou índices de conforto térmico adequados para a criação de bezerros, no período em estudo, mesmo para bezerros na fase inicial. Todos apresentaram condição de alerta ou perigo em todos os horários analisados. As coberturas apresentaram o mesmo comportamento para os índices ITU e ITGU, com valores diferentes estatisticamente para os diferentes horários de coleta, sendo o horário das $14 \mathrm{~h} 00 \mathrm{~min}$ o que apresentou maiores valores, corroborando resultados obtidos por SAMPAIO et al. (2009).

Comparando os valores obtidos para variável climática Temperatura Ambiente com aqueles de termoneutralidade, em que a situação de desconforto para bezerros acentua-se lentamente a partir de $18^{\circ} \mathrm{C}$, atingindo índices críticos a partir de $26^{\circ} \mathrm{C}$ (Vieira de Sá, apud SANTOS et al., 1993; KAWABATA, 2003), é possível afirmar que o bezerreiro exposto à sombra foi a instalação que apresentou menor temperatura ambiente, no período em estudo, que é considerado o mais crítico na região, devido às temperaturas máximas elevadas, amplitudes térmicas diárias elevadas e pouca chuva.

$\mathrm{O}$ uso do processamento de imagens termográficas infravermelhas mostrou-se uma ferramenta facilitadora da identificação de diferenças significativas de temperatura de superfície de cobertura do bezerreiro exposto à sombra em comparação àqueles expostos ao sol. Pela análise estatística, observa-se diferença significativa na temperatura de superfície, entre os tratamentos expostos ao sol, sendo possível constatar que a TFCB foi a que apresentou menores valores de temperatura de superfície dos abrigos expostos ao sol. Os resultados de temperatura de termovisor indicam variação no gradiente de temperatura da superfície interna das telhas em estudo (cores vermelhas e amarelas indicam maiores temperaturas e cores azul e rosa indicam temperaturas menores), figura 1. A colocação do sombrite contribuiu com a redução da temperatura da superfície interna da cobertura, no entanto, seu efeito não minimizou os índices de conforto térmico aferidos nos abrigos.

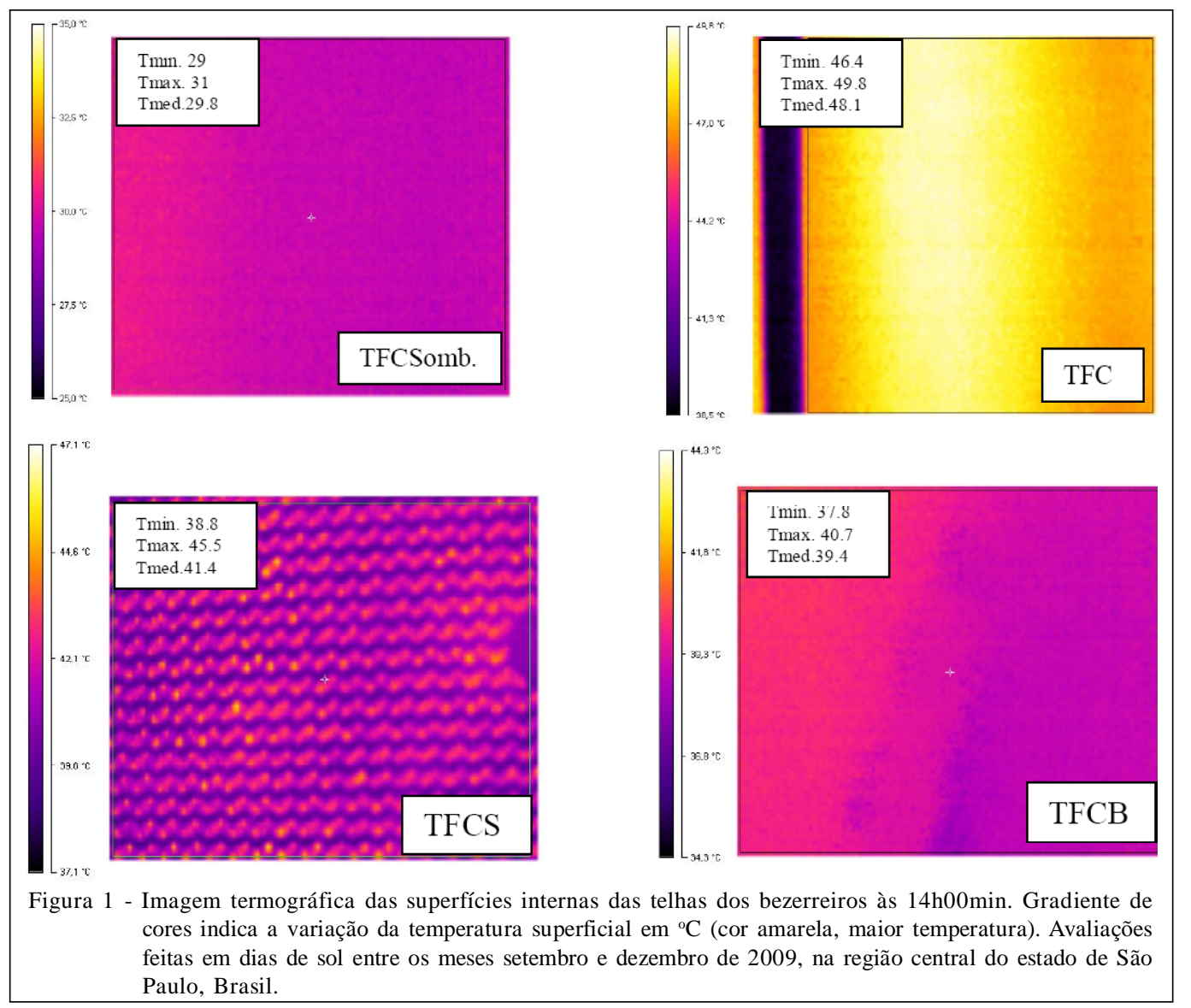

Ciência Rural, v.42, n.1, jan, 2012. 


\section{REFERÊNCIAS}

BAÊTA, F.C. Responses of lacting dairy cows to the combined effects of temperature, humidity and air velocity in the warm season. 1985. 218f. Tese (Doutorado em Structures and Enviroment) - Curso de Pós-graduação em Structures and Enviroment, University of Missouri.

BUFFINGTON, D.E. et al. Black globe-humidity comfort index for dairy cows. St Joseph: Transaction of the ASAE, 1977. 19p.

CAMPOS, A.T. et al. Análise térmica de abrigos individuais móveis e sombrite para Bezerros. Acta Scientiarum. Animal Sciences, v.27, n.1, p.153-161, 2005. Disponível em: <http:/ /periodicos.uem.br/ojs/index.php/ActaSciAnimSci/article/ viewFile/1261/693>. Acesso em: 01 set. 2011.

ESMAY, M.L. Principles of animal environment. Westport: Avi, 1969. 325p.

FURTADO, D.A. et al. Análise do conforto térmico em galpões avícolas com diferentes sistemas de acondicionamento. Revista Brasileira de Engenharia Agrícola e Ambiental, v.7, n.3, p.559-564, 2003. Disponível em: <http://www.scielo.br/ scielo.php?script=sci_arttext\&pid=S 1415 -
43662003000300025>. Acesso em: 01 set. 2011. doi: 10.1590/ S1415-43662003000300025.

KAWABATA, C.Y. Desempenho térmico de diferente tipos de telhados em bezerreiros individuais. 2003. $108 \mathrm{f}$. Dissertação (Mestrado em Zootecnia) - Curso de Pós-graduação em Zootecnia, Universidade de São Paulo, SP.

NÄÄS, I.A. et al. Avaliação térmica de telhas de composição de celulose e betumem, pintadas de branco, em modelos de aviários com escala reduzida. Engenharia Agrícola, v.21, n.2, p.121126, 2001.

SAMPAIO, C.A.P. et al. Temperaturas superficiais de telhas e sua relação com o ambiente térmico. In: CONGRESSO BRASILEIRO DE ENGENHARIA AGRÍCOLA, 38., 2009, Juazeiro/Petrolina,Brasil. Anais... Juazeiro(BA)/Petrolina (PE): SBEA, 2009. V.1. SANTOS, A.C. et al. Análise de diferentes formatos de bezerreiros individuais móveis, para região de Viçosa. Engenharia na Agricultura, v.2, n.7, p.1-8, 1993.

SILVA, R.G. Introdução à bioclimatologia animal. São Paulo: Nobel, 2000. 286p.

THOM, E.C. Cooling degree - day air conditioning, heating and ventilating. Transactions of the ASAE, v.55, n.7, p.65$72,1958$. 